\title{
QUALIDADE DA MADEIRA SERRADA NA REGIÃO DA QUARTA COLÔNIA DE IMIGRAÇÃO ITALIANA DO RIO GRANDE DO SUL
}

\author{
QUALITY OF THE SAWED WOOD IN THE AREA OF THE FOURTH COLONY OF ITALIAN \\ IMMIGRATION OF THE RIO GRANDE DO SUL STATE
}

\author{
Darci Alberto Gatto ${ }^{1}$ Elio José Santini ${ }^{2}$ Clovis Roberto Haselein ${ }^{2}$ Miguel Antão Durlo ${ }^{2}$ \\ RESUMO
}

Este estudo foi conduzido com o objetivo de avaliar a qualidade da madeira serrada produzida na Região da Quarta Colônia de Imigração Italiana no Rio Grande do Sul. Três empresas que processam madeiras de pinus foram analisadas com respeito à operação de desdobro e método de secagem empregados, e o teor de umidade da madeira industrializada. Constatou-se que a secagem ao ar livre é o principal método empregado na região, e os defeitos resultantes influenciam negativamente na qualidade da madeira serrada, o que sugere a necessidade de ajustes no método. No entanto, o teor de umidade médio da madeira está dentro dos padrões recomendados para a secagem ao ar livre. Em torno de $75 \%$ da madeira serrada na Região, quando úmida, foi classificada como de primeira qualidade. Depois de seca, contudo, apenas $45 \%$ das peças foram classificadas como de primeira qualidade e $45 \%$ de terceira, sendo os $10 \%$ restante incluídos nas categorias super, extra e segunda qualidade.

Palavras-chave: indústria da madeira; madeira serrada; qualidade da madeira; secagem ao ar.

\section{ABSTRACT}

This study was undertaken with the objective of evaluating the quality of the sawed wood produced in the Area of the Fourth Colony of Italian Immigration in Rio Grande do Sul. Three plants processing pine wood were investigated with respect to sawing and drying methods and moisture content of the industrial wood. The main method used was air seasoning and the resulting defects observed influenced the quality of the sawed wood negatively, suggesting the need of improving the process. However, the average moisture content was in agreement with the standards recommended for air seasoned wood. About $75 \%$ of the sawed wood of the area was classed as first when green. After drying, only $45 \%$ were first while $45 \%$ were of third grade. The remaining $10 \%$ were classed as super, extra or of second quality.

Key words: wood processing; sawing; air drying; wood quality.

\section{INTRODUÇÃO}

A região da Quarta Colônia é formada por pequenos municípios, tendo sua economia baseada em minifúndios rurais e em indústrias de pequeno porte baseados na produção rural e na produção florestal (IBGE, 2001). Na região, encontram-se 77 unidades consumidoras e transformadoras de madeira, classificadas em micro e pequenas empresas, com características e capital familiar, com baixo grau de industrialização. Destas, 37 empresas são processadoras de madeira, seja na industrialização de produtos florestais primários, como lenha, varas e toras, ou produtos secundários, parcialmente industrializados como pranchas, tábuas etc. O consumo de madeira serrada em 1999 foi de $6.783 \mathrm{~m}^{3}$ e $30.788 \mathrm{~m}^{2}$ de chapas e lâminas decorativas para produção de lambris $\left(118.370 \mathrm{~m}^{2}\right)$, assoalho $\left(67.300 \mathrm{~m}^{2}\right)$, esquadrias $\left(8.500 \mathrm{~m}^{2}\right)$, móveis $\left(3.819 \mathrm{~m}^{2}\right)$ e rodapés $(2.100 \mathrm{~m})$. Para a produção de $1.411 \mathrm{~m}^{3}$ de madeira serrada (tábuas, barrotes de construção, palanques e tramas) foram consumidos $2.750 \mathrm{~m}^{3}$ de toras e varas (Gatto, 2002).

No entanto, Gatto (2002) constatou que, nas empresas madeireiras da região, muitos aspectos tecnológicos são desconhecidos ou negligenciados durante o processamento da madeira, resultando em aproveitamento deficiente da matéria-prima e/ou na baixa qualidade do produto final. Para sanar essas

1. Engenheiro Florestal, MSc., Doutorando do Programa de Pós-Graduação em Engenharia Florestal, Centro de Ciências Rurais, Universidade Federal de Santa Maria, CEP 97105-900, Santa Maria (RS). darcigatto@yahoo.com

2. Engenheiro Florestal, Dr., Professor Adjunto do Departamento de Ciências Florestais, Centro de Ciências Rurais, Universidade Federal de Santa Maria, CEP 97105-900, Santa Maria (RS).

Recebido para publicação em 8/5/2003 e aceito em 17/11/2003. 
deficiências e tornar os produtos florestais mais competitivos no mercado consumidor, são necessárias investigações sobre a matéria-prima, os métodos e processos utilizados na industrialização da madeira.

Nesse contexto, realizou-se o presente trabalho com o objetivo avaliar a qualidade da madeira serrada produzida na região da Quarta Colônia, com respeito ao processo de desdobro, secagem e defeitos naturais, visando à sua classificação para o mercado geral.

\section{REVISÃO DE LITERATURA}

\section{Desdobro}

As toras se convertem em produtos úteis de madeira, mediante aplicação de um ou mais processos mecânicos que as transformam em peças menores, dando-lhes forma, tamanho e superfície requeridas para cada um de seus usos. O manejo eficiente e proveitoso das operações de industrialização requer que se trabalhe de maneira a se obter maior volume de material útil e valioso da tora. Essas operações também devem converter a tora em produtos que satisfaçam especificações de qualidade, dimensões e acabamento. Finalmente, as operações de industrialização da madeira devem realizar-se de tal maneira que a máquina não sofra desgaste excessivo, dano ou destruição e assim diminuindo os custos de manutenção ou de substituições (Brown \& Bethel, 1975).

A variação do desdobro influi significativamente no rendimento e qualidade da madeira. Serrarias com grande variação apresentam rendimentos menores, porque variações elevadas requerem maiores sobremedidas das peças serradas. A variação crítica no rendimento é a espessura. Segundo Ponce (1992) a mistura de produtos tem papel importante no rendimento, pois quanto maior o número de cortes menor é o rendimento. Assim, uma serraria que produz peças grandes geralmente tem maiores rendimentos que outra em que as os produtos são de menor tamanho. No entanto, a produção de peças grandes e pequenas resulta no aumento do rendimento.

Também a largura de corte produzida pela trava dos dentes de serra durante o desdobro da madeira tem sensível influência no rendimento. Um estudo conduzido nos Estados Unidos mostrou que a redução na largura de corte de uma serra circular de $9,5 \mathrm{~mm}$ para 7,14 mm aumentou em 7\% o rendimento (Ponce, 1992). É possível reduzir a espessura das lâminas de serra, tanto circulares como de fita, fazendo-se o tensionamento correto e pelo uso de guias.

A manutenção é outro fator que influencia significativamente no rendimento e qualidade da madeira serrada (Ponce, 1992). Equipamento bem cuidado pela manutenção preventiva apresenta menor variação na serração, de modo que as peças de madeira produzidas necessitam menores sobremedidas, o que aumenta o rendimento. A manutenção inclui o equipamento e as lâminas de serra, sendo que o trabalho realizado na sala de afiação influi diretamente na variação de serração, conseqüentemente, no rendimento.

As serras de fita necessitam para seu bom funcionamento de adequadas tensões internas e tensões de tração. O tensionamento interno da lâmina de serra consiste em alongar, segundo o comprimento, a parte central da lâmina, de modo que o dorso desta e a sua borda dentada fiquem ligeiramente mais curtas que a parte mediana. Já a tensão de tração das lâminas de serra de fita é obtida por meio de afastamento dos dois volantes que a suportam, e deve ser de aproximadamente $7 \mathrm{~kg} / \mathrm{mm}^{2}$ (Gomide,1974).

Nesse sentido, Menezes (1998) salienta que a definição da espessura da madeira a ser produzida deve ser bem planejada e levar em conta a qualidade da tora a ser processada, os volumes requeridos e o uso final da madeira. Quando não se dispõe de material homogêneo, faz-se necessário uma classificação da madeira antes do empilhamento que pode ser manual ou automático.

Eleotério et al. (1996), estudando a variabilidade na espessura de peças de madeira produzidas por serra circular múltipla SCM. 5.350 e SCM.2, encontraram, respectivamente, média de 27,08 mm e 26,77 mm de espessura, com variância de $0,109 \mathrm{~mm}$ e $0,160 \mathrm{~mm}$. No mesmo estudo, não foi encontrada relação entre a variabilidade da espessura com as larguras das peças.

Lopes (2000), pesquisando a variação da espessura de madeira serrada de Eucalyptus grandis produzida com uma serra de fita dupla, regulada para $28 \mathrm{~mm}$, encontrou uma espessura média de 27,63 mm 
com desvio-padrão de 0,414 mm, apresentando valores máximo e mínimo de $28,85 \mathrm{~mm}$ e de $26,35 \mathrm{~mm}$, respectivamente.

\section{Secagem}

Nos diferentes processos de transformação da madeira maciça em produtos industrializados, a secagem é a fase intermediária que mais contribui para agregar valor ao produto final. Contudo, levantamentos divulgados em 1964 e 1974 relatam que a falta de atenção da indústria para com a secagem é a principal causa do baixo padrão de qualidade dos produtos à base de madeira. A partir da década de 80, verificou-se uma evolução tecnológica em relação ao assunto, por meio da geração de conhecimentos nos principais centros de pesquisa, do aumento e aprimoramento da força de trabalho, e da incorporação de máquinas e equipamentos modernos (Ducatti et al., 2001).

A secagem da madeira é o processo da redução do seu teor de umidade, a fim de levá-la a um teor de umidade definido, com o mínimo de defeitos, no menor tempo possível e de uma forma economicamente viável, para o uso a que se destina (Martins, 1988).

$\mathrm{Na}$ atualidade, vários métodos de secagem podem ser empregados para secar a madeira, desde os mais simples, como ao ar livre, até os mais sofisticados em termos de equipamentos e sistemas de controle. Dentre os normalmente utilizados no sul do País (Santini, 1992), encontra-se a secagem ao ar livre, desumidificação, convencional e à alta temperatura.

A secagem ao ar livre consiste em empilhar a madeira em local ventilado, preferencialmente coberto, a fim de protegê-la da incidência dos raios solares e precipitações, fazendo-se o controle do teor de umidade em intervalos regulares até que atinja o valor que as condições climáticas da região permitirem. Para tanto, podese usar o método-padrão de empilhamento que consiste em dispor as tábuas lado a lado, formando camadas superpostas, separadas por meio de sarrafos ou tabiques, para permitir a passagem do ar entre elas e transferir a umidade da madeira para o ambiente (Martins, 1988). O espaçamento entre eles deve ser entre 25 a 40 vezes a espessura da tábua, dependendo do tipo de madeira (Stumpp, 1992).

Outro tipo de empilhamento, usado eventualmente em empresas de pequeno porte instaladas em regiões tropicais, é o tipo tesoura, que consiste em dispor as peças de forma inclinada, apoiadas a uma estrutura de madeira. Essa opção é muito utilizada em lugares úmidos, sobretudo como pré-secagem, em razão da alta velocidade de secagem que apresenta. Além disso, a confecção das pilhas é bastante rápida, e dispensa a colocação de separadores, pois estes já fazem parte da armação. Apresenta desvantagens como tendência a empenos do tipo torcimento e arqueamento, em razão da falta de restrição lateral; a parte superior seca mais rápido que a inferior, causando desuniformidade de umidade ao longo da peça; a maior velocidade de secagem pode causar rachaduras, sobretudo em regiões de clima seco (Martins, 1988).

A secagem ao ar livre depende de fatores ambientais, que não são controláveis, como temperatura, umidade relativa e velocidade do ar. Apesar disso, pode-se interferir sobre o processo, manipulando fatores como largura da pilha, espessura dos sarrafos separadores, a ocupação horizontal das pilhas e o arranjo físico do pátio de secagem (Jankowsky, 1992). O uso de cobertura protege a madeira da ação dos raios do sol e das precipitações, evitando rachaduras de topo e outros defeitos (Santini, 1992). As fundações das pilhas proporcionam apoio e boa ventilação ao material em secagem, e devem estar a aproximadamente $50 \mathrm{~cm}$ acima do nível do solo.

Quando da adoção da secagem ao ar livre, deve-se considerar, em princípio, a direção dos ventos predominantes, a localização do pátio, evitando-se barreiras aos ventos e outros acidentes geográficos que possam criar condições desfavoráveis, como lagos, rios ou áreas maldrenadas (Jankowsky, 1992). De acordo com Stumpp (1992), as pilhas devem ser dispostas de forma que o vento principal as atinja de lado e não de topo. Dessa forma, o ar consegue passar no meio da pilha e transportar as partículas do vapor d'água da madeira para o ambiente.

$\mathrm{Na}$ secagem ao ar livre, a utilização de equipamentos é limitada, e o processo é de simples 
acompanhamento. No entanto, o alto volume em estoques gera custos elevados. Outro fator limitante é a dificuldade na programação de produção, uma vez que o processo depende especialmente de variáveis nãocontroláveis (Jankowsky, 1992).

Segundo Jankowsky (1992), a qualidade da madeira seca começa a ser obtida a partir de sua preparação para a secagem (classificação da matéria-prima e empilhamento) e termina com o controle final de qualidade do produto final (madeira seca).

\section{Defeitos}

Como defeitos da madeira são consideradas todas as anomalias da forma do tronco da árvore, da sua seção transversal, como também da estrutura e da cor da madeira que possam reduzir, restringir ou mesmo anular sua utilização. Os defeitos naturais podem ser na forma e seção transversal do tronco, na estrutura anatômica da madeira, condicionados pelo ambiente, alteração da cor da madeira que não sejam causados por fungos (Grosser, 1980).

O manejo da floresta pode ser uma contribuição importante para a melhoria da qualidade da madeira. Nesse sentido, o espaçamento influi no ritmo de crescimento, na proporção de madeira juvenil e na queda natural dos ramos; o desbaste, além de influir na produtividade final, ajuda a controlar a quantidade de madeira juvenil, a presença de nós e a proporção de lenho tardio, dentre outras características; e a desrama é efetuada primordialmente para diminuir a nodosidade (Galvão, 1992).

Já os defeitos de desdobro são alterações nas dimensões da peça de madeira acima dos padrões permitidos, resultado de uma operação de serragem malfeita. Os principais defeitos de serragem são a sobremedida, o desbitolamento e o esmoado. A sobremedida é o excesso em espessura, largura e/ou comprimento. O desbitolamento é a variação na espessura ou na largura de uma mesma peça, ocasionada por serragem mal feita. O esmoado é a ausência de madeira, originada por qualquer motivo, na quina da peça de madeira; quina morta (ABNT, 1991b).

A grandeza dos problemas decorrentes das tensões de crescimento, durante a conversão das toras, pode ser extremamente variável de árvore para árvore e mesmo entre toras de uma mesma árvore. Assim, enquanto o desdobro de uma tora ocorre com relativa facilidade, produzindo altos rendimentos, uma outra pode prender a serra, produzir madeira empenada, rachada e com baixos rendimentos (Fernandes, 1982).

Segundo Durlo \& Marchiori (1992), o aumento de volume ou o inchamento da madeira se deve, sobretudo, à inclusão de moléculas de água nos espaços submicroscópicos localizados entre as micelas, tendo como consequiência o seu afastamento. De idêntica forma, porém, em sentido contrário, a redução do volume de uma peça se explica pela saída de moléculas de água dos espaços mencionados, ocasionando a aproximação das micelas e, conseqüentemente, a retração da madeira. Essa retração, quando abrupta, tende a aumentar ainda mais a incidência de defeitos produzidos pelas tensões de crescimento ou pelas tensões de secagem.

Dessa forma, as tensões que se desenvolvem na madeira durante a saída da água são a causa básica dos defeitos de secagem. Dentre os principais defeitos resultantes da secagem incluem-se os empenamentos do tipo encanoamento, arqueamento, encurvamento e torcimento; as rachaduras, o encruamento e o colapso (Galvão \& Jankowsky, 1985).

\section{MATERIAIS E MÉTODOS}

O presente trabalho foi conduzido na região conhecida como "Quarta Colônia de Imigração Italiana no Rio Grande do Sul" que compreende os municípios de Silveira Martins, Ivorá, São João do Polêsine, Faxinal do Soturno, Nova Palma, Dona Francisca e Pinhal Grande, localizados na região Central do Rio Grande do Sul, entre o Planalto e a Depressão Central.

Para avaliar a qualidade da madeira processada, foram coletadas informações em três serrarias instaladas na região cujas características dos equipamentos, processamento e matéria-prima são apresentadas 
na Tabela 1. Além disso, consideram-se também a variação em espessura das peças por ocasião do corte, a nodosidade, os defeitos de secagem e a classificação do produto.

Na serraria 1, as toras de Pinus sp. permanecem depositadas no pátio, em contato direto com o solo, até serem desdobradas, com casca, num período de tempo máximo em 48 horas após o abate.

No pátio da segunda serraria, existe um tipo de isolamento que evita o contato direto da madeira com o solo apenas próximo ao equipamento. Essa empresa funciona sobretudo nos períodos de condições climáticas desfavoráveis, quando os funcionários ficam impossibilitados de executar trabalhos externos.

$\mathrm{Na}$ terceira serraria estudada, as toras são depositadas no pátio desprovido de qualquer tipo de isolamento e, posteriormente, serradas com a casca, em torno de sete a oito dias após o abate.

TABELA 1: Características das serras de fita e parâmetros observados por ocasião do desdobro de madeira de Pinus sp.

TABLE 1: Characteristics of band saws and observed headrig parameters for pine wood processing.

\begin{tabular}{lllll}
\hline Parâmetros & \multicolumn{1}{c}{ Serraria 1 } & \multicolumn{1}{c}{ Serraria 2 } & \multicolumn{1}{c}{ Serraria 3 } \\
\hline Marca e ano da serra & Abicht, 1977 & Seibert, 1975 & Turbina, 1985 \\
Modelo & horizontal & horizontal & Vertical \\
Diâmetro dos volantes (m) & 1,10 & 1,00 & 0,80 \\
Espessura da lâmina (mm) & 1,10 & 1,10 & $0,90-1,10$ \\
Travamento & recalque & torção & recalque \\
Largura de corte (mm) & 2,26 & $2,50-3,00$ & 2,30 \\
Comprimento das toras (m) & 2,70 & $2,50-2,70$ & 2,75 \\
\hline
\end{tabular}

\section{Desdobro e defeitos}

A madeira de pinus (Pinus sp) foi utilizada para avaliar a qualidade do desdobro, por ser a matériaprima mais importante da região. Para tanto, estudou-se o material procedente de três empresas diferentes, e desdobrado por meio de serras de fita. Para avaliar a qualidade das tábuas, considerou-se a variação em espessura ao longo do seu comprimento, sendo o primeiro ponto de medição tomado a $40 \mathrm{~cm}$ da extremidade, e os demais a cada $50 \mathrm{~cm}$, totalizando cinco pontos de medição por peça. Em cada ponto foram efetuadas duas medições, uma na posição da entrada da lâmina de serra e outra na saída. Para cada serra de fita, foram avaliadas em torno de cem peças, imediatamente após serradas, de modo a permitir a identificação de irregularidades nos diferentes pontos da tábua e evitar que eventuais defeitos de secagem fossem atribuídos ao desdobro.

A largura de corte (fio de serra) foi obtida com paquímetro digital com precisão de $0,01 \mathrm{~mm}$. Para as serras com travamento por recalque, mediu-se o valor da trava individual dos dentes, e para a lâmina com travamento por torção foram medidas as inclinações do dente para a esquerda e para direita, e somados à espessura da lâmina.

\section{Secagem e defeitos}

Para avaliar os defeitos naturais e de secagem, foram analisados dois lotes distintos em três serrarias, um antes (madeira úmida) e outro após a secagem ao ar livre (madeira seca). Nos lotes de madeira úmida, foram analisados apenas os defeitos naturais, ao passo que nos lotes de madeira seca, além dos defeitos naturais, foram também quantificados os defeitos resultantes da secagem.

$\mathrm{Na}$ avaliação da qualidade da madeira serrada, adotou-se os procedimentos da Associação Brasileira de Normas Técnicas (ABNT, 1991a), observando-se sempre a pior face da peça.

As três empresas avaliadas empregam o método de secagem ao ar livre, sendo que duas delas utilizam o empilhamento tipo tesoura, e outra, o tipo gaiola. Nos lotes de madeira seca mediram-se os empenamentos do tipo arqueamento, encurvamento e encanoamento; as rachaduras de topo e a amplitude de variação do teor de umidade final. Nesses lotes, observou-se também a ocorrência de outros defeitos como a presença de 
manchas, bolsa de resina, presença de medula e esmoado, número e proporção de nós (\%) bem como a situação dos pátios de secagem.

A madeira produzida pelas três empresas foi avaliada por meio de amostragem e classificada de acordo com critérios utilizados para classificação da madeira serrada de coníferas provenientes de reflorestamentos (ABNT, 1991a).

\section{RESULTADOS E DISCUSSÃO}

\section{Defeito de desdobro}

A variação na espessura das peças de madeira serrada nas três serrarias estudadas é mostrada na Tabela 2. Observa-se que a espessura média foi praticamente a mesma nas três serras, mas entre peças detectou-se uma diferença significativa a 5\% de probabilidade para as três empresas avaliadas.

TABELA 2: Informações relativas à variação em espessura da madeira nas três serras de fita.

TABLE 2: Information regarding sawing variability of the three band saws

\begin{tabular}{lccc}
\hline Estatísticas & Serra 01 & Serra 02 & Serra 03 \\
\hline Número de medições & 1010 & 980 & 1000 \\
Espessura da madeira & & & \\
Média (mm) & 26,15 & 25,73 & 25,37 \\
Mínimo (mm) & 21,01 & 21,00 & 20,37 \\
Máximo (mm) & 32,46 & 29,30 & 29,85 \\
Desvio padrão (mm) & 0,999 & 1,013 & 1,166 \\
F calculado & & & \\
Entre peças & $25,02^{*}$ & $14,23^{*}$ & $8,21^{*}$ \\
Dentro das peças & 0,591 & 0,220 & $3,65^{*}$ \\
Entrada e saída & 2,184 & 0,083 & $44,38^{*}$ \\
\hline
\end{tabular}

* Significativo a 5\% de probabilidade de erro; medições obtidas a 40, 90, 140, 190, $240 \mathrm{~cm}$ ao longo do comprimento da peça.

A variação em espessura dentro das peças e na entrada/saída da lâmina foi significativamente diferente apenas na serra da empresa 3. As prováveis causas para a variação observada na espessura das peças são o desgaste do bitolador, desnível ou desgaste nos roletes do carrinho transportador de toras, falta de tensão na lâmina de serra, ou o uso inadequado das guias (Brown \& Bethel, 1975).

Outro fato observado foi a presença de serragem na superfície da tábua, o que pode ser resultado de um pequeno avanço por dente, baixa velocidade de alimentação associada à alta velocidade da lâmina. Desse modo, a serragem produzida é facilmente perdida entre os dentes, causando um atrito entre a lâmina e a madeira que pode afetar a tensão interna da fita.

Com base nos problemas observados por ocasião do desdobro, deduz-se que as empresas não fazem os trabalhos adequados de manutenção nos equipamentos de corte.

\section{Nodosidade}

A nodosidade é um fator limitante na utilização da madeira influenciando no rendimento e na qualidade do produto final madeireiro.

$\mathrm{Na}$ Tabela 3, podem-se constatar uma grande proporção de nós, um elevado diâmetro médio e o grande número de nós por metro quadrado. Os lotes úmidos e secos não apresentaram variações no número de nós por $\mathrm{m}^{2}$ e no diâmetro destes. À exceção da serraria 1 na qual as peças serradas apresentaram uma diminuição do diâmetro médio dos nós do lote úmido para seco. É provável que no lote seco a madeira proceda de uma floresta mais densa (maior número de árvores por ha). Também se observa, na Figura 1, uma grande porcentagem de nós soltos e cariados. Dessa forma, pode-se inferir que as florestas dessa região são pouco 
manejadas com vistas à qualidade da madeira, resultando em material que produzirá perdas e baixa qualidade na sua industrialização.

TABELA 3: Número, diâmetro e proporção de nós em amostras de madeira úmida (antes da secagem) e seca (depois da secagem) procedentes de três serrarias da região.

TABLE 3. Number, diameter and knot proportion in samples of green and air seasoned wood coming from the three lumber mills.

\begin{tabular}{|c|c|c|c|c|c|c|c|}
\hline \multirow[t]{2}{*}{ Características } & \multicolumn{2}{|c|}{ Serraria 1} & \multicolumn{2}{|c|}{ Serraria 2} & \multicolumn{2}{|c|}{ Serraria 3} & \multirow[t]{2}{*}{ Total } \\
\hline & Úmida & Seca & Úmida & Seca & Úmida & Seca & \\
\hline \multicolumn{8}{|l|}{ Número de nós $/ \mathrm{m}^{2}$} \\
\hline Média & 10,7 & 14,4 & 10,3 & 12,1 & 9,9 & 12,4 & 11,5 \\
\hline Mínimo & 1,2 & 0,0 & 3,1 & 3,7 & 0,0 & 0,0 & 0,0 \\
\hline Máximo & 27,3 & 47,2 & 21,9 & 20,6 & 21,0 & 34,6 & 47,2 \\
\hline Desvio padrão & 5,1 & 8,6 & 3,6 & 4,2 & 4,6 & 8,9 & 6,5 \\
\hline $\mathrm{N}^{\mathrm{o}}$ de amostras & 100 & 100 & 100 & 100 & 100 & 109 & 609 \\
\hline \multicolumn{8}{|l|}{ Diâmetro dos nós (mm) } \\
\hline Média & 33,6 & 19,0 & 39,4 & 35,9 & 36,1 & 26,8 & 33,4 \\
\hline Mínimo & 3 & 4 & 5 & 5 & 4 & 4 & 3 \\
\hline Máximo & 130 & 90 & 180 & 165 & 140 & 95 & 180 \\
\hline Desvio padrão & 21,1 & 10,5 & 24,3 & 27,2 & 23,9 & 15,2 & 23,4 \\
\hline $\mathrm{N}^{\mathrm{o}}$ de observações & 677 & 411 & 678 & 933 & 632 & 356 & 3687 \\
\hline \multicolumn{8}{|l|}{ Proporção de nós (\%/m) } \\
\hline Média & 31 & 27 & 40 & 43 & 33 & 34 & 35 \\
\hline Mínimo & 5 & 0 & 9 & 8 & 0 & 0 & 0 \\
\hline Máximo & 80 & 84 & 83 & 81 & 98 & 80 & 98 \\
\hline Desvio padrão & 16 & 18 & 16 & 16 & 26 & 18 & 20 \\
\hline $\mathrm{N}^{\mathrm{o}}$ de amostras & 100 & 100 & 100 & 100 & 100 & 109 & 609 \\
\hline
\end{tabular}

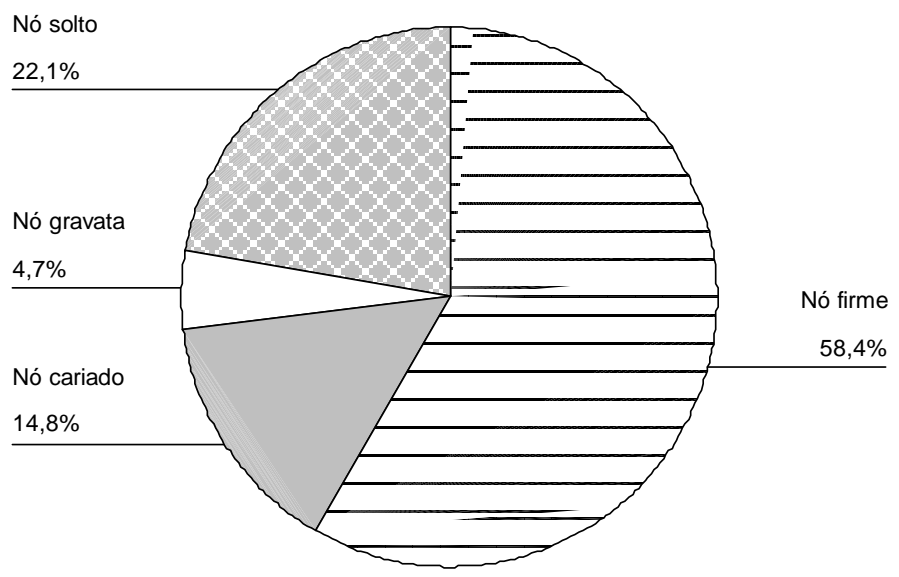

FIGURA 1: Quantificação dos principais tipos de nós observados na madeira.

FIGURE 1: Type of knots observed in the wood.

\section{Secagem}

Para a secagem, foram estudadas três empresas da região que utilizavam o método de secagem ao ar livre, sendo os mesmos lotes secos da Tabela 3.

$\mathrm{Na}$ empresa 1, são separadas as peças de madeira para a secagem ao ar livre e empilhadas na forma de tesoura. A extremidade inferior da tábua apresentava um isolador de madeira evitando o contato direto com 
o solo. O pátio de secagem dessa empresa não se encontrava em posição recomendável de secagem, encontrando-se num local baixo e pouco ventilado.

Já na empresa 2, o pátio está localizado num ponto elevado e bem-ventilado. A madeira era empilhada na forma de tesoura, com separadores (tabiques) de $25 \mathrm{~mm}$ de espessura entre as tábuas. A extremidade inferior das tábuas apresentava um isolador de madeira, evitando o contato da tábua com o solo.

$\mathrm{Na}$ empresa 3, o pátio de secagem estava num ponto elevado bem-ventilado, tendo apenas uma barreira a oeste do pátio. O sistema de empilhamento utilizado por esse empresário era do tipo "gaiola" de quatro lados. As tábuas eram empilhadas sem separadores, produzindo na superfície de contato das peças de madeira o surgimento da mancha azul em cerca de 60,5\% das tábuas (Tabela 4). A pilha não apresentava cobertura e se encontrava a apenas $13 \mathrm{~cm}$ do solo.

TABELA 4: Variação do teor de umidade da madeira seca ao ar livre em três empresas da região da Quarta Colônia de Imigração Italiana do RS no período de outubro a dezembro.

TABLE 4: Moisture content variation of the air dried lumber in three lumber mills of the 4th Colony of Italian Immigration of the Rio Grande do Sul from October to December.

\begin{tabular}{lcccc}
\hline Teo de Umidade $(\%)$ & Empresa 1 & Empresa 2 & Empresa 3 \\
\hline Número de observações & 33 & 42 & 36 \\
Média & 16,42 & 17,13 & 15,43 \\
Mínimo & 13,9 & 12,1 & 12,3 \\
Máximo & 19,3 & 26,0 & 19,0 \\
Desvio-padrão & 1,42 & 3,43 & 1,36 \\
Teste F & $1,06^{\text {ns }}$ & $0,06^{\text {ns }}$ & $3,20^{\text {ns }}$ \\
Tempo de exposição (dias) & 40 & 20 & 30 \\
\hline
\end{tabular}

Em que: $n s$ = não significativo a $5 \%$ de probabilidade de erro.

O teor de umidade médio observado na madeira das três empresas estudadas (Tabela 4), oscilou entre 15,4 e $17,1 \%$. Nessa faixa de umidade o material pode ser considerado seco, pois para o método de secagem ao ar livre, o teor de umidade final na região varia entre 15 a 20\% (Santini, 1992).

Observa-se, na Tabela 5, que as empresas 1 e 3 apresentaram maior incidência de defeitos como encurvamento e arqueamento, em razão da secagem de madeira estreita e redimensionada. As empresas $1,2 \mathrm{e}$ 3 apresentaram, respectivamente, $23 \%, 8 \%$ e $38 \%$ das peças de seus lotes com encurvamento superior a $0,5 \%$. Já no arqueamento as mesmas empresas apresentaram, respectivamente, 4\%, $1 \%$ e $27 \%$ das peças de seus lotes com arqueamento superior a $0,5 \%$. Por outro lado, a empresa 2 apresentou incidência de encanoamento, superior $4 \mathrm{~mm}$ em $4 \%$ das peças do lote um, defeito que pode ser atribuído à secagem de madeira larga. Da mesma forma, observa-se grande incidência de madeira manchada, crítica para a empresa 3. Esse defeito ocorre especialmente em razão da ausência de separadores secos entre as tábuas.

TABELA 5: Porcentagem de peças defeituosas.

TABLE 5: Percentile of defected pieces.

\begin{tabular}{l|c|c|c}
\hline Defeitos & Empresa 1 & Empresa 2 & Empresa 3 \\
\hline Torcimento & 44 & 8 & 11 \\
Encanoamento & 0 & 10 & 0 \\
Encurvamento & 54 & 21 & 62,4 \\
Arqueamento & 20 & 1 & 47,7 \\
Rachadura de topo & 30 & 33 & 22 \\
Mancha azul & 25 & 28 & 60,5 \\
\hline
\end{tabular}

De maneira geral, constata-se que os métodos de empilhamento foram inadequados, resultando em secagem com grande incidência de defeitos. Já o teor de umidade final não apresentou diferença significativa entre as posições (Tabela 4), indicando uma homogeneização da secagem na pilha. 
Analisando-se a secagem empregada pelos empresários pesquisados, sugere-se a utilização de empilhamento-padrão ("gradeado") detalhado por Martins (1988) que, para a secagem ao ar livre, é mais eficiente no controle das tensões de secagem, com conseqüente diminuição de defeitos.

\section{Classificação com base na qualidade}

Para classificação de qualidade da madeira serrada seguiram-se as recomendações da Associação Brasileira de Normas Técnicas (ABNT, 1991a, 1991b) que consideram os defeitos naturais, de desdobro e de secagem da madeira serrada.

As Figuras 2 e 3 demonstram respectivamente a quantidade percentual dos tipos de madeira encontrados para madeira úmida e seca. Observando as duas Figuras, pode-se notar que, da passagem do lote úmido para os lotes secos, há uma diminuição na porcentagem de madeira de melhor qualidade e um conseqüente aumento para a madeira de pior qualidade. Isso ocorre em razão do surgimento de defeitos de secagem que acarretam uma reclassificação nos lotes. Os defeitos poderiam ser minimizados com o maior cuidado por parte dos empresários com a secagem da madeira.

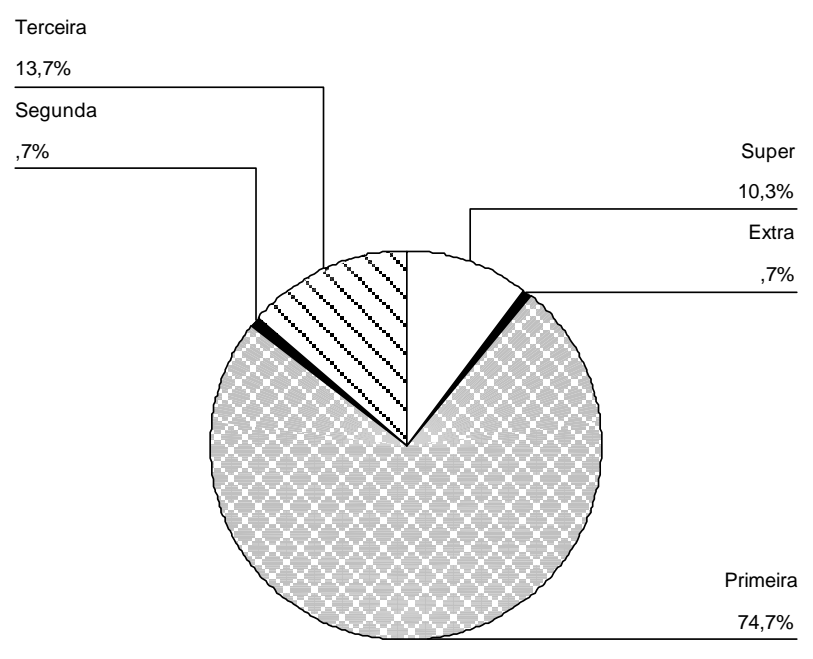

FIGURA 2: Classes de qualidade para madeira úmida.

FIGURE 2: Green wood grades.

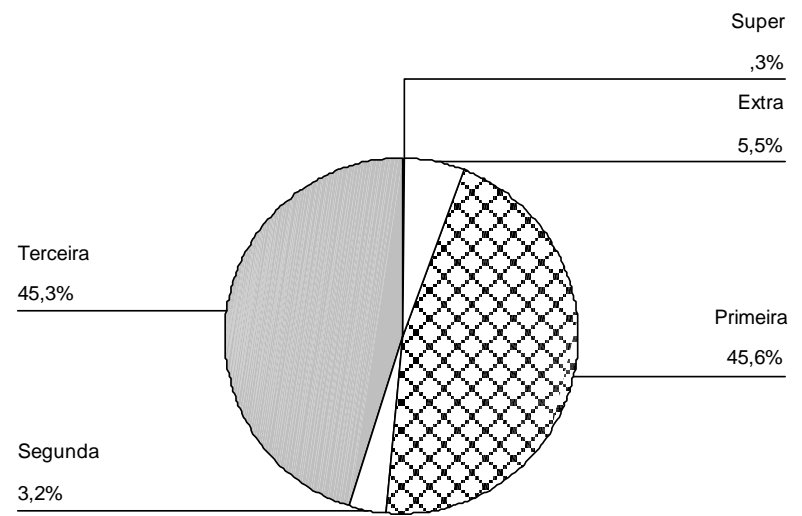

FIGURA 3: Classes de qualidade para madeira seca.

FIGURE 3: Air seasoned wood grades.

Dessa forma, pode-se classificar a madeira produzida na região, sobretudo, como madeira de primeira qualidade $(74,7 \%)$ quando úmida. Depois de seca, verificou-se uma queda na qualidade da madeira serrada, 
sendo que $45,6 \%$ foi classificada como de primeira, e $45,3 \%$ de terceira qualidade, conforme mostram as Figuras 2 e 3.

\section{CONCLUSÕES}

Os resultados deste trabalho permitem as seguintes conclusões:

A operação de desdobro produziu uma grande incidência de defeitos, resultando em heterogeneidade da madeira serrada com conseqüente perda de rendimento;

Em torno de $75 \%$ da madeira recém-serrada é classificada como de primeira qualidade, e depois de seca há uma queda de qualidade para aproximadamente $45 \%$. No caso da madeira classificada como de terceira qualidade, houve um aumento de 13,7 pra $45,3 \%$;

Em razão da alta percentagem de defeitos observada na madeira seca ao ar livre, que influiu negativamente na qualidade da madeira serrada, ajustes ou mudanças no método são recomendados. Todavia, o teor de umidade médio final da madeira se encontra, próximo aos valores de umidade de equilíbrio da região.

\section{AGRADECIMENTOS}

Os Autores agradecem ao Projeto "Floresta Colonial", convênio entre a Universidade Federal de Santa Maria, Brasil e a Universidade Rural de Viena, Áustria, pelo financiamento desta pesquisa.

\section{REFERÊNCIAS BIBLIOGRÁFICAS}

ASSOCIAÇÃO BRASILEIRA DE NORMAS TÉCNICAS . NBR 11700: madeira serrada de coníferas provenientes de reflorestamento, para uso geral. Rio de Janeiro, 1991a. 6p.

ASSOCIAÇÃO BRASILEIRA DE NORMAS TÉCNICAS . NBR 12297: madeira serrada de coníferas provenientes de reflorestamento, para uso geral : medição e quantificação de defeitos. Rio de Janeiro, 1991b. 6p.

BROWN, N. C.; BETHEL, J. S. La industria maderera. Mexico: Limusa, 1975. 388 p.

DURLO, M. A.; MARCHIORI, J. N. C. Tecnologia da madeira: retratibilidade. Santa Maria: UFSM, CEPEF/FATEC, 1992. 33p (Série Técnica, 10).

DUCATTI, M. A.; JANKOWSKY, I. P.; ANDRADE, A. Condições da secagem convencional em indústrias madeireiras no município de Tietê, SP. Scientia Forestalis, n.59, p 101-113, jun. 2001.

ELEOTÉRIO, J. R.; STORCK, L., LOPES; S. J. Caracterização de peças de madeira produzidas em serraria visando o controle de qualidade. Ciência Florestal, v. 6, n. 1, p 89-99, 1996.

FERNANDES, P. de S. Variação de densidade da madeira e suas relações com as tensões de crescimento em progênies de Eucalyptus urophilla S. T. Blake. 1982. 85f. Dissertação (Mestrado em Engenharia Florestal) ESALQ, Universidade de São Paulo, Piracicaba, 1982.

GALVÃO, A. P. M.; JANKOWSKY, I. P. Secagem racional da madeira. São Paulo, 1985. 111p.

GALVÃO, P. M. Aspectos fundamentais do uso e da comercialização da madeira de pinus no Brasil. In: SIMPÓSIO FLORESTAL DO RIO GRANDE DO SUL - TECNOLOGIA DA MADEIRA, 2., 1992, Santa Maria. Anais... Santa Maria: CEPEF/FATEC, 1992. p. 30-39.

GATTO, D. A. Avaliação quantitativa e qualitativa da utilização madeireira na região da Quarta Colônia de imigração italiana no Rio Grane do Sul. 2002. 108f. Dissertação (Mestrado em Engenharia Florestal) - Centro de Ciências Rurais, Universidade Federal de Santa Maria, Santa Maria, 2002.

GOMIDE, J. L. Serraria. Viçosa: Universidade Federal de Viçosa, Escola Superior de Florestas, 1974. 119p. (apostila).

GROSSER, D. Defeitos da madeira. Curitiba: FUPEF, 1980. 63p. (Serie Técnica, 2).

IBGE - INSTITUDO BRASILEIRO DE GEOGRAFIA E ESTATISTICA. Cadastro central de empresas: web site do Instituto Brasileiro/ empresas.htm, 2001. Disponível em: www.ibge.gov.br .

JANKOWSKY, I. P. O controle do processo de secagem. In: SIMPÓSIO FLORESTAL DO RIO GRANDE DO SUL TECNOLOGIA DA MADEIRA, 2., 1992, Santa Maria. Anais... Esteio: UFSM/AGEFLOR/ CEPEF/FATEC, 1992. p. 9-29. 
LOPES, M. C. Estágio supervisionado em Engenharia Florestal. 2000. 47f. Relatório (Graduação em Engenharia Florestal) - Universidade Federal de Santa Maria, Santa Maria, 2000.

MARTINS, V. A. Secagem de madeira serrada. Brasília: Gutenberg, 1988. 56p.

MENDES, A. de S.; MARTINS, V. A.; MARQUES, M. H. B. Programa de secagem para madeiras brasileiras. Brasília, 1998. p. 23-28.

MENEZES, L. F. Desdobro, secagem e beneficiamento da madeira de eucalipto: experiência da Flosul. In: SEMINÁRIO INTERNACIONAL SOBRE PRODUTOS SÓLIDOS DE MADEIRA DE ALTA TECNOLOGIA, 1. E ENCONTRO SOBRE TECNOLOGIAS APROPRIADAS DE DESDOBRO, SECAGEM E UTILIZAÇÃO DA MADEIRA DE EUCALIPTO, 1., 1998, Belo Horizonte. Anais... Belo Horizonte: SIF/UFV/DEF, 1998. p 261-265.

PONCE, R. H. Tecnologia de desdobro de pinus e eucaliptos a busca da competitividade. In: SIMPÓSIO FLORESTAL DO RIO GRANDE DO SUL - TECNOLOGIA DA MADEIRA, 2., 1992, Esteio. Anais... Santa Maria: UFSM/AGEFLOR/CEPEF/FATEC, 1992. p. 154-162.

SANTINI, E. J. Métodos de secagem de madeira. In: SEMINÁRIO SOBRE SECAGEM DE MADEIRA, 1., 1990, Santa Maria. Anais... Santa Maria: UFSM/CEPEF/FATEC, 1992. p. 47-59.

STUMPP, E. Curso de secagem. In: SEMINÁRIO SOBRE SECAGEM DE MADEIRA, 1., 1990, Santa Maria. Anais... Santa Maria, 1992. p.75-100. 